\title{
CDISC SDTM Contact Role for Clinical Study Terminology
}

National Cancer Institute

\section{Source}

National Cancer Institute. CDISC SDTM Contact Role for Clinical Study Terminology. NCI

Thesaurus. Code C127257.

Terminology associated with the contact role for clinical study codelist of the Clinical

Data Interchange Standards Consortium (CDISC) Study Data Tabulation Model (SDT M). 